\title{
ELABORAÇÃO, CARACTERIZAÇÃO E ACEITABILIDADE DE "IOGURTE" DE SOJA COM ADIÇÃO DE PREBIÓTICO
}

\section{PREPARATION, CHARACTERIZATION AND ACCEPTABILITY OF "YOGURT" SOY WITH ADDED PREBIOTIC}

\author{
Alana Kolling1; Daniel Lehn ${ }^{1}$, Claucia Fernanda Volken de Souza ${ }^{1}$ \\ ${ }^{1}$ Centro Universitário Univates - Lajeado - RS - Brasil lehn@ univates.br
}

\section{Resumo}

A dieta tem sido reconhecida como ferramenta importante na prevenção de diversas doenças $e$ agravos não transmissíveis, além de poder reduzir o risco de doenças. A soja tem sido muito consumida como auxiliar no controle do colesterol sanguíneo, na diminuição dos sintomas da menopausa, na prevenção da osteoporose, como substituto do leite de vaca por pessoas que apresentam intolerância a lactose, além de outros benefícios já comprovados cientificamente. Diante da importância dos alimentos funcionais na dieta habitual, o objetivo do presente estudo foi elaborar um "iogurte" de soja com adição de prebiótico, caracterizar e avaliar sua aceitação entre alunos dos cursos de graduação da Univates. O iogurte foi elaborado a partir do leite de soja, fermento lácteo, frutoligossacarídeo (FOS), polpa de morango e açúcar. Para a diferenciação das amostras foi utilizado os cereais aveia, chia e linhaça, além de uma amostra comercial para comparação. Posteriormente foram realizadas análise físico-químicas e sensoriais. Os valores encontrados para carboidratos foram em média 9,4\%, gorduras totais 1,3\%, proteínas 3,03\%, cinzas $0,82 \%$ e umidade $85,41 \%$. As amostras elaboradas se mostraram menos calóricas que a comercial, sendo um produto de valor nutricional considerável, além de poder suprir algumas necessidades nutricionais. A análise sensorial demonstrou que houve diferença significativa entre as amostras, sendo que apenas uma amostra apresentou boa aceitabilidade. Portanto, o iogurte elaborado é uma ótima opção para o consumo, não só pelo menor valor calórico, mas também por apresentar mais fibras, devido ao cereal e ao prebiótico adicionado em sua composição.

Palavras-chave: iogurte; soja; análise sensorial.

\section{Introdução}

A dieta tem sido reconhecida como ferramenta importante na prevenção de diversas doenças e agravos não transmissíveis, e há diversos estudos para verificar a eficácia de certos alimentos na redução do risco de doenças (ROSA et al., 2010). 
Os alimentos funcionais são compostos por substâncias biologicamente ativas, que podem estimular processos fisiológicos ou metabólicos, reduzindo então o risco de doenças e manutenção da saúde. Para oferecer efeitos positivos, os alimentos funcionais devem fazer parte da alimentação diária dos indivíduos, para que os compostos ativos se mantenham constantemente presentes no organismo (ANJO, 2004).

A soja pode ser considerada como um alimento completo, uma vez que apresenta em sua composição proteínas, carboidratos, lipídios e resíduos, além de vitaminas e sais minerais (AMARAL, 2006). Atualmente, a soja, por suas propriedades funcionais, tem sido bastante consumida como auxiliar no controle do colesterol sanguíneo, na diminuição dos sintomas da menopausa, na prevenção da osteoporose, como substituto do leite de vaca por pessoas que apresentam intolerância a lactose ou algum tipo de alergia ao leite comum, além de outros benefícios já comprovados cientificamente (PIMENTEL et al., 2005). O grão é considerado fonte de proteínas, ácidos graxos poliinsaturados, minerais, vitaminas do complexo $\mathrm{B}$, fibras e isoflavonas, grupo de compostos fenólicos responsáveis por proporcionar benefícios à saúde (SILVA et al., 2009b).

Devido ao seu alto valor nutritivo a soja tem sido uma importante matéria-prima para a produção de derivados alimentícios, sendo uma excelente alternativa para a nutrição humana em geral, especialmente para pessoas impossibilitadas de consumir produtos de origem animal (MAIA et al., 2006).

Para Carreiro (2007) prebióticos podem ser descritos como um ingrediente alimentar não digerível que afeta beneficamente seu anfitrião, estimulando seletivamente o crescimento e/ou atividade de uma ou algumas (boas) bactérias no cólon, trazendo os consequentes benefícios à saúde. Por isso os prebióticos não somente proporcionam aumento potencial do número de bactérias benéficas no intestino grosso de humanos, predominantemente os lactobacilos e as bifidobactérias, mas também aumentam sua atividade metabólica através do fornecimento de substrato fermentável (BIELECKA et al., 2002).

Novas tendências alimentares justificam o desenvolvimento de alimentos funcionais, devido a hábitos adquiridos pelas pessoas que tendem a alimentar-se de maneira pouco balanceada e pobre em nutrientes essenciais ao organismo (SALGADO e ALMEIDA, 2009). Além disso, outros fatores vêm estimulando o desenvolvimento de alimentos funcionais, dos quais se destacam os avanços na tecnologia de alimentos e ingredientes, o aumento da expectativa de vida, o elevado custo dos serviços de saúde, o aumento da consciência dos consumidores, que desejando manter uma vida mais saudável, optam por melhores hábitos (KOMATSU et al., 2008).

Segundo Saad (2011), o papel cada vez mais influente da indústria alimentícia sobre a dieta e estilo de vida da população vem acompanhado do desafio de atender a demanda dos consumidores 
por produtos que sejam saborosos, visualmente atrativos e que, ao mesmo tempo visem a saúde e o bem-estar.

Apesar dos benefícios associados ao consumo do grão de soja, este possui baixa aceitação entre os brasileiros devido, principalmente, ao aroma e sabor considerados desagradáveis. Enzimas lipoxigenases presentes nos grãos atuam sobre ácidos graxos poliinsaturados contidos na leguminosa, conferindo à soja e seus derivados sabor relatado como sabor de ranço, remetendo ao sabor de feijão cru, causando rejeição pelos consumidores (BEHRENS e SILVA, 2004). A análise sensorial é de extrema importância, uma vez que é a única forma de avaliar e caracterizar sensorialmente o produto, já que não existe nenhum instrumento capaz de substituir os sentidos humanos e, consequentemente, avaliar a aceitação de produtos alimentícios (KINOUCHI et al., 2002).

Diante da importância dos alimentos funcionais na dieta habitual devido aos benefícios na prevenção de doenças e promoção a saúde, o objetivo do presente estudo foi elaborar e avaliar a aceitação de diferentes formulações de "iogurte" de soja com adição de prebiótico.

\section{Material e Métodos}

Desenvolvimento das formulações de bebidas fermentadas de soja

Os "iogurtes" de soja foram preparados no laboratório de técnica dietética da Univates, com os seguintes ingredientes: 1 litro de leite soja, $40 \mathrm{~g}$ de fermento lácteo marca Bio Rich® ${ }^{\circledR} \operatorname{com} L$.

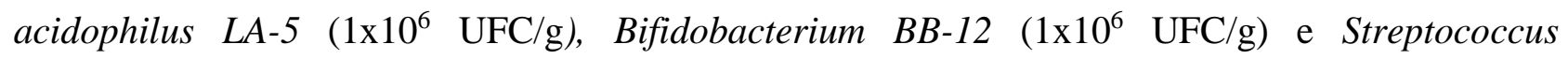
thermophilus, além de $7 \mathrm{~g}$ de FOS da marca Fosvita®. O período de elaboração foi a manhã do dia da análise sensorial, permanecendo em temperatura de refrigeração até o momento da análise.

Para conferir identidade (sabor) ao iogurte foi elaborada uma calda de morango, a partir de 30 g de açúcar refinado, $200 \mathrm{~g}$ de polpa de morango e $200 \mathrm{~mL}$ de água. A mistura foi aquecida até a fervura, sendo mantida até a redução do volume total à $40 \%$ do volume inicial. Após, foi misturada a calda de morango, a aveia, linhaça e chia, o corante e o aromatizante nas quantidades indicadas na Tabela 1, cada um separadamente para diferenciar as amostras e finalizá-las.

O leite de soja e o fermento lácteo foram misturados e depois submetidos à fermentação à $42^{\circ} \mathrm{C}$ por 7 a 10 horas até o "iogurte" apresentar consistência firme. O pH do iogurte nesse momento foi de 7 . 
Tabela 1 - Distribuição dos constituintes dos “iogurtes” de soja elaborados

\begin{tabular}{|c|c|c|c|}
\hline Componente & Amostra "A" & Amostra "B" & Amostra "C" \\
\hline Extrato hidrossolúvel de soja - Batavo Naturis (L) & 1 & 1 & 1 \\
\hline Fermento lácteo Bio Rich $®(\mathrm{mg})$ & 400 & 400 & 400 \\
\hline FOS $(\mathrm{g})$ & 7 & 7 & 7 \\
\hline Água $(\mathrm{mL})$ & 100 & 100 & 100 \\
\hline Polpa concentrada de morango $(\mathrm{g})$ & 200 & 200 & 200 \\
\hline Corante vermelho Mix Coralim ® (gotas) & 4 & 4 & 4 \\
\hline Aromatizante Duas Rodas Industrial @ (gotas) & 12 & 12 & 12 \\
\hline Aveia $(g)$ & 30 & ------ & ------ \\
\hline Linhaça Dourada (g) & ------ & 30 & ------ \\
\hline Chia $(\mathrm{g})$ & ----- & ------ & 30 \\
\hline
\end{tabular}

Fonte: DA AUTORA, 2013

Durante a produção das bebidas, foram adotadas boas práticas de fabricação, para a segurança necessária ao produto final, evitando-se contaminações físicas, químicas e microbiológicas. As bebidas foram desenvolvidas no Laboratório de Lácteos, Cárneos e Farináceos da Univates, e avaliadas sensorialmente no Laboratório de Análise Sensorial da Univates.

Fluxograma de produção dos "iogurtes"

A Figura 1 ilustra o processo de produção dos "iogurtes" de soja.

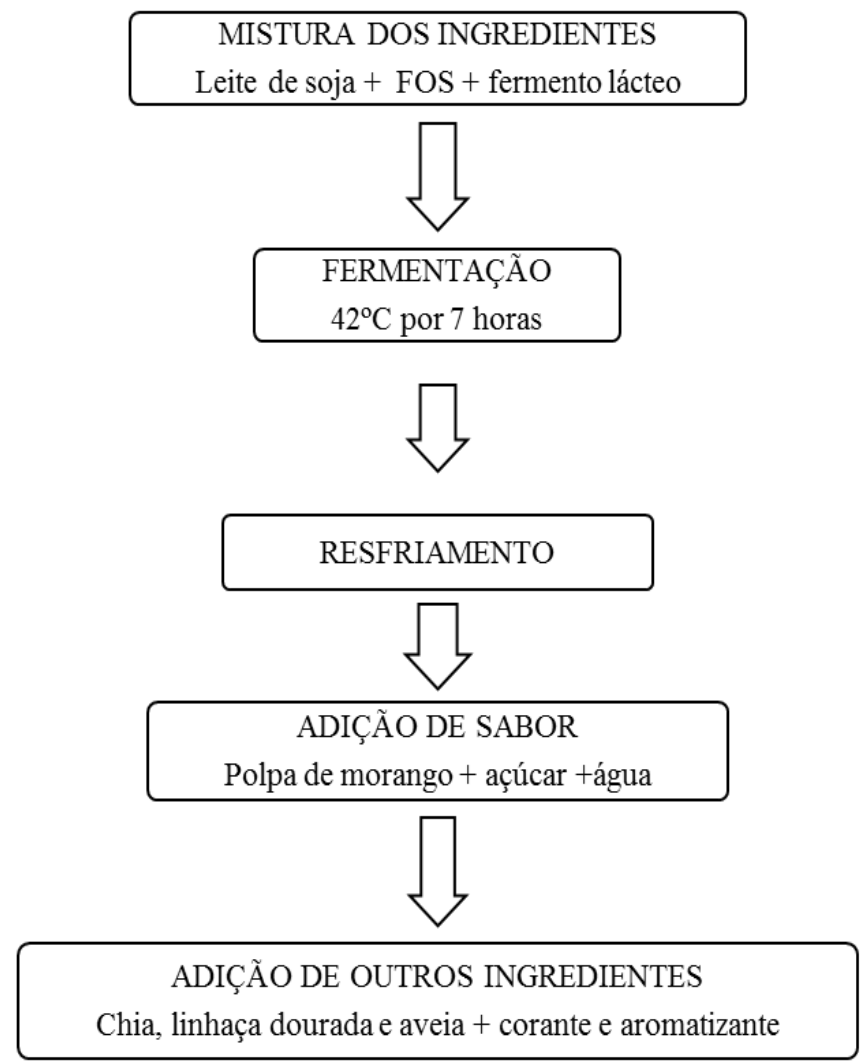

Figura 1 - Fluxograma de produção das amostras. 
As amostras elaboradas foram analisadas pelo laboratório de análises Unianálises da Univates, utilizando os seguintes critérios: para carboidratos a metodologia utilizada foi de POFQ UNI042, Ver. 3 - de acordo com RDC $\mathrm{n}^{\circ}$ 360, 2003 - ANVISA; para proteínas foi utilizada a POFQ - UNI006, Ver. 3 - de acordo com RDC n 360, 2003 - ANVISA; e para lipídeos foi utilizada a POPFQ - UNI082, Ver. 4 - de acordo com Instrução Normativa nº 68, 2006 - MAPA.

\section{Análise Sensorial}

A análise sensorial dos "iogurtes" de soja foi realizada no Laboratório de Análise Sensorial do Centro Universitário UNIVATES, Lajeado, RS, em cabines individuais sob luz branca e à temperatura ambiente, com as amostras dispostas em copos plásticos descartáveis de $50 \mathrm{~mL}$ e servidas em prato plástico descartável. As amostras em porções padronizadas (aproximadamente 20 g) foram codificadas com números aleatórios de 3 dígitos e apresentadas aos provadores de forma balanceada e aleatorizada. Junto com as amostras, foi servida água mineral à temperatura ambiente para limpeza do palato, foi entregue uma ficha do teste de aceitação, contendo uma escala hedônica estruturada de 9 pontos, variando de 1 "desgostei muitíssimo" à 9 "gostei muitíssimo" nos aspectos: aparência, odor, sabor, textura e impressão global, além de uma ficha de intenção de compra e frequência de consumo de "iogurte de soja".

O painel sensorial foi composto por 60 provadores não treinados de ambos os sexos, recrutados aleatoriamente entre os alunos dos cursos de graduação da Univates. Somente participaram do experimento os provadores que assinaram o Termo de Consentimento Livre e Esclarecido (TCLE), aprovado pelo comitê de Ética em Pesquisa (COEP) da Univates, sob o registro número 175.637.

Para o cálculo de Índice de Aceitabilidade (IA) do produto, foi adotada a expressão IA $(\%)=$ A x 100 / B, em que, $\mathrm{A}$ = nota média obtida para o produto e $\mathrm{B}=$ nota máxima dada ao produto. $\mathrm{O}$ IA com boa repercussão tem sido considerado > 70\% (DUTCOSKY, 2009).

\section{Análise estatística}

Os resultados da análise sensorial das amostras de "iogurte" de soja foram avaliados pela Análise de Variância (ANOVA) e verificada a significância dos modelos pelo teste F. Nos modelos significativos em relação às amostras, as médias foram comparadas entre si pelo teste de Tukey, ao 
nível de 5\% de significância. Os cálculos estatísticos foram efetuados utilizando o software Statistica®versão 7.0.

\section{Resultados e Discussão}

\section{Análise físico-química do "iogurte" de soja com adição de prebiótico}

A Tabela 2 apresenta os resultados obtidos para análise da composição química dos “iogurtes” com adição de prebiótico juntamente com o iogurte comercial.

Os componentes do iogurte comercial estão descritos a seguir: água, açúcar, pedaços de morango e framboesa, extrato de soja, amido modificado, fosfato tricálcico, fermentos, aromatizantes, corante natural antocianina e conservante sorbato de potássio (* informação extraída da embalagem do produto).

Tabela 2 - Composição centesimal das amostras

\begin{tabular}{ccccc}
\hline ANÁLISES & $\begin{array}{c}\text { Amostra } \\
\text { "A" }\end{array}$ & $\begin{array}{c}\text { Amostra } \\
\text { "B" }\end{array}$ & Amostra "C" & Comercial* \\
\hline Carboidratos (\%) & 9,3 & 9,1 & 9,8 & 16 \\
Lipídeos totais & 1,5 & 1,2 & 1,2 & 1,7 \\
(\%) & 3,3 & 3,0 & 2,8 & 2,9 \\
Proteínas (\%) & 0,8 & 0,8 & 0,8 & -- \\
Cinzas (\%) & 85 & 85,8 & 85,4 & --- \\
Umidade (\%) & (* informação extraída da embalagem do produto). \\
\hline \multicolumn{4}{r}{ Fonte: DA AUTORA, 2013 }
\end{tabular}

Em relação aos carboidratos, a amostra "C" foi a mais expressiva $(9,8 \%)$, sugerindo ser devido ao cereal aveia, que de acordo com a tabela TACO (2011), apresenta maior concentração de carboidrato em relação aos demais cereais. A amostra (comercial) apresenta um maior teor de carboidratos devido aos componentes da fórmula.

Os "iogurtes" elaborados, assim como a amostra comercial, não apresentam lactose devido aos componentes de sua formulação, constituindo-se como uma ótima opção para portadores da intolerância a este carboidrato.

O valor médio encontrado para carboidratos no presente estudo foi de 9,4\%, sendo inferior a dados da literatura, pois Hauly et al. (2005), ao trabalharem com "iogurte" de soja com adição de frutoligossacarídeos encontrou um valor médio de 16,2\% de carboidrato, próximo ao valor da amostra comercial estudada. Pelo fato desse estudo apresentar extrato de soja como matéria prima, supõe-se por esse motivo ter apresentado um maior percentual de carboidrato já que as amostras estudadas foram elaboradas com leite de soja pronto. Já no estudo de Martins et al. (2013), que elaboraram um iogurte de extrato hidrossolúvel de soja com adição de inulina, encontrando um teor 
de carboidratos de 2,8\%, sendo inferior ao encontrado no presente estudo. Esta diferença pode se dar pela adição de açúcar na composição do iogurte em estudo, já que o estudo de Martins et al. (2013) apresenta em sua composição adoçante.

Em relação aos lipídeos, a amostra "A" foi a que apresentou um teor mais alto de lipídeos com 1,5\%, sugerindo ser pelo componente chia. De acordo com Capitanni et al. (2012), em $100 \mathrm{~g}$ de chia é encontrada de 30 g a 38,6 g de óleo e 60,7 g a 67,8 g de ácido oleico. Já Tosco (2004) relata que a quantidade de óleo varia entre $32 \%$ a $39 \%$ de óleo na semente. Essas variações podem ocorrer em função de diversos fatores como a cultivação da semente e condições climáticas de cultivo.

O valor médio de lipídeos encontrado nas amostras foi de 1,3\%, sendo inferior ao mesmo estudo de Hauly et al. (2005), que encontraram 2,0\%, tal fato pode se justificar pela presença do extrato hidrossolúvel de soja, já que de acordo com a tabela Taco (2011) este possui um teor aproximado de 26,2\% de gordura. Assim como Martins et al. (2013), encontraram um valor de $1,7 \%$ no teor de gordura de sua formulação, sendo também superior ao presente estudo.

Em relação ao teor de proteínas, a amostra "A" também foi a mais expressiva apresentando 3,3\% em sua composição, sugerindo ser devido a chia. De acordo com Tosco (2004), a quantidade de proteína da semente de chia pode variar entre $19 \%$ e $23 \%$, apresentando conteúdo de proteínas um pouco superior ao encontrado em outras sementes como a aveia $(15,3 \%)$ e linhaça $(14,1 \%)$ (TACO, 2011).

O valor médio encontrado para proteína foi de 3,0\%, sendo muito inferior a um estudo de Miguel et al. (2010), em que elaboraram um "iogurte" de soja a partir do extrato desengordurado de soja e polpa de morango, que atingiu um valor médio de $17,8 \%$ de proteína podendo esta diferença ser justificada pelo emprego de extrato desengordurado, que contribui para um aumento expressivo do valor proteico do "iogurte". Em outro estudo feito por Martins et al. (2013) um "iogurte" de extrato hidrossolúvel de soja com adição de inulina apresentou 3,6\% de proteína, sendo pouco superior ao iogurte estudado, provavelmente devido ao maracujá adicionado na formulação, pois de acordo com a tabela Taco (2011), o maracujá apresenta 2,0\% de proteínas já o morango 0,9\% em sua composição.

Quanto ao teor de cinzas das amostras, a amostra que mais se destacou foi a "A" com 0,8\%. A média das amostras estudadas foi de 0,8\%, sendo superior ao estudo de Martins et al. (2013), onde foi encontrado 0,5\% de cinzas. Segundo Silva et al. (2009a), as cinzas podem ser consideradas como uma medida geral de qualidade de alimentos, uma vez que maiores teores de cinzas retratam maiores teores de minerais e de acordo com Chaves et al. (2004) é frequentemente utilizada como critério na identificação dos alimentos. 
Para o teor de umidade encontrado, a amostra "B" foi a mais expressiva entre elas com 85,8\%, sendo superior ao encontrado em um estudo feito por Fuchs et al. (2005), onde foi elaborado um "iogurte" de soja suplementado com prebiótico apresentando 77,8\% de umidade. O estudo feito por Martins et al. (2013) encontrou 85,2\% de umidade em sua amostra de iogurte, sendo inferior ao estudo.

A Tabela 3 mostra o valor calórico das amostras, calculado a partir das composições centesimais dos "iogurtes" elaborados. Para a amostra comercial, o dado foi extraído da embalagem.

Tabela 3 - Valor calórico das amostras do estudo

\begin{tabular}{cc}
\hline Amostra & $\begin{array}{c}\text { Valor calórico (kcal) } \\
\mathbf{/ 1 0 0 g}\end{array}$ \\
\hline Amostra "A" & 63,9 \\
Amostra "B" & 59,2 \\
Amostra "C" & 61,2 \\
Amostra Comercial & 91,0 \\
\hline Fonte: DA AUTORA, 2013
\end{tabular}

Comparando-se o valor calórico dos "iogurtes" elaborados, não houve grande diferença entre as amostras. Já a amostra comercial apresentou um valor calórico maior devido aos componentes de sua formulação.

\section{Análise Sensorial}

A Tabela 4, apresenta os resultados da análise sensorial das formulações de "iogurte" de soja com adição de prebiótico.

Tabela 4 - Resultados da avaliação sensorial dos "iogurtes” de soja com adição de prebiótico e amostra comercial

\begin{tabular}{cccccc}
\hline Amostra & Cor & Textura & Sabor & Aparência & Aceitação Global \\
\hline "A" & $5,8 \pm 1,89^{\mathrm{c}}$ & $5,7 \pm 1,85^{\mathrm{c}}$ & $5,6 \pm 1,92^{\mathrm{b}}$ & $5,6 \pm 1,82^{\mathrm{c}}$ & $5,7 \pm 1,73^{\mathrm{c}}$ \\
"B" & $6,4 \pm 1,69^{\mathrm{b}}$ & $6,5 \pm 1,59^{\mathrm{b}}$ & $5,8 \pm 1,64^{\mathrm{b}}$ & $6,2 \pm 1,69^{\mathrm{b}}$ & $6,2 \pm 1,49^{\mathrm{bc}}$ \\
"C" & $6,7 \pm 1,53^{\mathrm{b}}$ & $6,6 \pm 1,54^{\mathrm{b}}$ & $6,0 \pm 1,79^{\mathrm{b}}$ & $6,5 \pm 1,67^{\mathrm{b}}$ & $6,3 \pm 1,62^{\mathrm{b}}$ \\
Comercial & $7,4 \pm 1,39^{\mathrm{a}}$ & $7,3 \pm 1,48^{\mathrm{a}}$ & $7,2 \pm 1,58^{\mathrm{a}}$ & $7,5 \pm 1,32^{\mathrm{a}}$ & $7,4 \pm 1,32^{\mathrm{a}}$ \\
\hline
\end{tabular}

*Resultados correspondem a média \pm desvio padrão de 60 provadores. Médias com letras diferentes, na mesma coluna, apresentam diferença significativa entre si $(p \leq 0,05)$, conforme resultado do teste de Tukey. Fonte: DA AUTORA, 2013

A amostra melhor pontuada entre os atributos foi a comercial, com notas superiores a 7, uma vez que a escala hedônica varia de 9,0-1,0. 
Houve diferença significativa entre as amostras "A" e comercial em relação a cor, sugerindo estar ligada a cor do cereal chia presente na amostra elaborada. Segundo Bobbio e Bobbio (1995) a primeira impressão que se tem de um alimento é geralmente visual, sendo a cor um dos aspectos fundamentais na qualidade e aceitação do produto.

Em relação à textura, também houve diferença significativa entre estas amostras, também sugerindo estar relacionada a cor do cereal chia presente na amostra elaborada.

As amostras "A", "B" e "C" tiveram diferença significativa em relação a amostra comercial, no quesito sabor, podendo ser em função da amostra comercial não apresentar algum cereal em sua composição, apenas o aroma de frutas vermelhas. Para Drewnowisk (1997), o sabor exerce no consumidor a principal influência para a escolha de um alimento.

As amostras "A" e comercial apresentaram diferença significativa em relação à aparência, sugerindo ser pela amostra comercial não apresentar cereal em sua composição, apenas pedaços da fruta. Segundo Meilgaard et al. (1991), o primeiro atributo apreciado pelo homem é a aparência, seguido pelo odor, consistência, textura e sabor.

\section{Aceitabilidade dos “iogurtes" de soja}

A Tabela 5 mostra os resultados (em \%) do índice de aceitabilidade dos atributos avaliados das amostras de "iogurte" de soja.

Tabela 5 - Resultados (em \%) do índice de aceitabilidade dos atributos avaliados das amostras de "iogurte" de soja

\begin{tabular}{|c|c|c|c|c|c|}
\hline Amostra & Cor & Textura & Sabor & Aparência & Aceitação Global \\
\hline "A" & 64,8 & 63,9 & 62,2 & 62,8 & 63,0 \\
\hline "B" & 71,5 & 72,6 & 65,0 & 69,6 & 68,5 \\
\hline "C" & 74,3 & 73,5 & 66,7 & 72,4 & 70,0 \\
\hline Comercial & 82,4 & 81,1 & 80,7 & 83,9 & 82,0 \\
\hline
\end{tabular}

Os "iogurtes" de soja elaborados não apresentaram de forma geral uma boa aceitação sensorial de sabor e aspectos visuais como cor, aparência e textura. Porém a amostra "C" foi a que teve o melhor índice de aceitabilidade com 70\%, apresentando boa repercussão de acordo com Dutosky (2009).

Dentre todos os aspectos sensoriais, a amostra "C" foi a melhor pontuada em relação às amostras elaboradas. 


\title{
4. Conclusão
}

As amostras elaboradas com os cereais chia e linhaça não obtiveram boa aceitabilidade, porém a amostra elaborada com a aveia apresentou uma boa aceitação, sendo também melhor pontuada em todos os aspectos sensoriais. Essa amostra também apresentou valor calórico menor em comparação com a amostra comercial, sendo uma ótima opção para o consumo, não só pelo valor calórico, mas também por apresentar mais fibras, devido ao cereal adicionado em sua composição e também ao prebiótico. E para aumentar a aceitação, pode ser modificado o teor de aveia e o teor do aromatizante, que pode aumentar a nota dos atributos sabor e textura. Sugere-se o teste de estabilidade e avaliação de custos como próxima etapa do desenvolvimento deste produto.

\begin{abstract}
The diet has been recognized as an important tool in the prevention of various diseases and noncommunicable diseases, and can reduce the risk of diseases. Soy has long been consumed as a helper in the control of blood cholesterol, the reduction of menopausal symptoms, prevention of osteoporosis, as a substitute for cow's milkfor people who are intolerant to lactose, and other scientifically proven benefits. Given the importance of functional foods in the usual diet, the aim of this study was to develop a "yogurt" Soy with added prebiotic, characterize and evaluate its acceptance among students of Nutrition Univates RS. The yogurt was made from soy milk, dairy yeast, FOS, strawberry pulp and sugar. For the differentiation of the samples was used cereal oats, flax and chia, as well as a commercial sample. Were subsequently carried out physico-chemical and sensory. The values found for carbohydrates has averaged 9.4\%, 1.3\% total fat, 3.03\% protein, $0.82 \%$ ash and $85.41 \%$ moisture. The prepared samples were less caloric than commercial, being a product of considerable nutritional value, and can supply some nutritional needs. Sensory analysis showed that there were significant differences between the samples, and only one sample showed good acceptability. Therefore, yogurt is a great option designed for consumption, not only by the lower calorific value, but also provide more fiber, due to the cereal and added prebiotic composition.
\end{abstract}

Key-words: yogurt; soybean; sensory analysis.

\section{Referências}

AMARAL, V. M. G. A importância da soja como alimento funcional para qualidade de vida e saúde. $2006.86 f$. Dissertação (Mestrado Profissional em Engenharia Mecânica/ Gestão da Qualidade Total) - Faculdade de Engenharia Mecânica, Universidade Estadual de Campinas, Campinas.

ANJO, D. F. C. Alimentos funcionais em angiologia e cirurgia vascular. Jornal Vascular Brasileiro, v. 3, n. 2, p. 145154,2004 
BEHRENS, J. H. E SILVA, M. A. A. P. Atitude do consumidor em relação à soja e produtos derivados. Ciência e Tecnologia dos Alimentos, v. 24, n. 3, p.431-439, 2004.

BIELECKA, M.; BIEDRZYCKA, E.; MAJKOWSKA, A.; JUSKIEWICZ, J.; WRÓBLEWSKA, M. Effect of nondigestible oligosaccharides on gut microecosytem in rats. Food Research International, v. 35, p. 139-144, 2002. http://dx.doi.org/10.1016/S0963-9969(01)00175-2

BOBBIO, F. O.; BOBBIO, P. A. Manual de laboratório de química dos alimentos. São Paulo: Livraria Varela, 1995.

CAPITANNI, M.I. O.; SPORTORNO, V.; NOLASCO, S.M.; TOMÁS, M.C. Caracterização físico-química e funcional dos subprodutos de semente de Chia (Salvia hispanica L.) da Argentina. Ciência e Tecnologia de Alimentos, v. 45, p. 94-102, 2012.

CARREIRO, D. M. Entendendo a importância do processo alimentar. 2 ed. São Paulo: Editora Metha, 2007.

CHAVES, M. C. V.; GOUVEIA, J. P. G., LEITE, J. C. A.; ALMEIDA, F. A.; SILVA, F. L. H. Caracterização físicoquímica do suco da acerola. Revista de Biologia e Ciências da Terra; v. 4, n. 2, 2004.

DREWNOWSKI, A. Taste preferences and food intake. Annual Review of Nutrition, v. 17, n 1, p.237-253, 1997. http://dx.doi.org/10.1146/annurev.nutr.17.1.237

DUTCOSKY, S. D. Análise sensorial de alimentos. Curitiba: Champagnat, 2009.

FUCHS, R. H. B., BORSATO, D., BONA, E. "Iogurte" de soja suplementado com oligofrutose e inulina. Ciência e Tecnologia de Alimentos, Campinas, v. 25, n.1, p. 175-181, 2005. http://dx.doi.org/10.1590/S010120612005000100029

HAUlY, M. C. O.; FUCHS, R. H. B.; PRUDÊNCIO FERREIRA, S. H. Suplementação de iogurte de soja com frutooligossacarídeos: características probióticas e aceitabilidade. Revista de Nutrição. v. 18, n. 5, p. 613-622, 2005. http://dx.doi.org/10.1590/S1415-52732005000500004

INSTITUTO ADOLFO LUTZ (IAL). Normas Analíticas do Instituto Adolfo Lutz: Métodos químicos e físicos para análise de alimentos. São Paulo: 4 ed., 1 ed. digital, 2008.

KINOUCHI, F. L.; CARDELlO, H. M. A. B.; ROSSI, E. A.; JÚNIOR, R. T. Aceitação do "iogurte" de soja entre adolescentes. Alimentos e Nutrição, v. 13, p. 131-142, 2002.

KOMATSU, T. R; BURITI, F. C. A; SAAD, S. M. I.; Inovação, persistência e criatividade superando barreiras no desenvolvimento de alimentos probióticos. Revista Brasileira de Ciências Farmacêuticas, v. 44, n. 3, p. 329-347, 2008. http://dx.doi.org/10.1590/S1516-93322008000300003

MAIA, M.J.L; ROSSI, E.A; CARVALHO, R.B. Qualidade e rendimento do leite de soja da unidade de produção de derivados da soja - Unisoja FCF-Ar/UNESP. Alimentos e Nutrição, v. 17, n. 1, p. 65-72, 2006.

MARTINS, G. H.; KWIATKOWSI, A.; BRACH, L.; SRUTKOSKE, C. L. Q.; HAMINIUK, C. W. I. Perfil físicoquímico, sensorial e reológico de iogurte elaborado com extrato hidrossolúvel de soja e suplementado com inulina. Revista Brasileira de Produtos Agroindustriais. v. 15, n. 1, p. 93-102, 2013.

MEILGAARD, M.; CIVILLE, G.V.; CARR, B. T. Sensory evaluation techniques. Boca Raton: CRC, 1991.

MIGUEL, P. R.; MARMITT, T.; SCHLABITZ, C.; HAUSHILD, F. A. D.; SOUZA, C. F. V. Desenvolvimento e caracterização de "iogurte" de soja sabor morango produzido com extrato de soja desengordurado enriquecido com cálcio. Alimentos e Nutrição, v. 21, n. 1, p. 57-63, 2010.

PIMENTEL, C. V. M. B.; FRANCKI, V. M.; GOLLUCKE, A. P. B.; Alimentos Funcionais: Introdução as principais substancias bioativas em alimentos. São Paulo: Livraria Varela, 2005.

ROSA, C. O. B; LEITE, J. I. A. Alimentos Funcionais e Dislipidemias. In Costa, Neuza Maria Brunoro; Rosa, Carla de Oliveira. Alimentos funcionais: Componentes bioativos e efeitos fisiológicos. Rio de Janeiro: Editora Rubio, 2010.

SAAD, S. M. I; CRUZ, A. G; FARIA, J. A. F. Probióticos e Prebióticos em Alimentos: Fundamentos e Aplicação Tecnológica. São Paulo: Editora Varela, 2011. 
SAlGADO, J. M.; ALMEIDA, M. A. Mercado de alimentos funcionais: desafios e tendências. Sociedade Brasileira de Alimentos Funcionais (SBAF). 2009. Disponível em: <www.sbaf.org.br/_artigos/200806_Mercado_ Alimentos_Funcionais_-_Desafios_Tendencias.pdf>. Acesso em: 06 nov. 2013.

SILVA, J. S.; SOUZA, H. N.; GUIMARÃES, M. G. C.; CARVALHO, R. V. S.; SANTOS, V. R. M.; AZEVÊDO, L. C. Caracterização de uma nova variedade de Tamarindo (Tamarindus indica) cultivada na Bahia. IV Congresso de Pesquisa e Inovação da Rede Norte e Nordeste de Educação Tecnológica. Belém - PA - 2009a.

SILVA, K. M. C.; LIMA, F. R. B.; RITA, R. C. O.; SILVA, C. G. M. Soja (Glycine max): benefícios a saúde humana com melhor qualidade de vida. IX JORNADA DE ENSINO, PESQUISA E EXTENSÃO. SEMANA NACIONAL DE CIÊNCIA E TECNOLOGIA. 2009b.

TABELA Brasileira de Composição de Alimentos - TACO. $4^{\text {a }}$ Edição. Campinas. SP, 2011.

TOSCO, G. Os benefícios da Chia em humanos e animais. Revista Atualidades Ornitológicas, v. 119, n. 7, 2004.

Submetido em18 dez. 2013, Aceito para publicação em 23 jun. 2014, Publicado em 28 dez. 2014. 